\title{
Preparation and Characterization of Pressureless Sintered Alumina/5 vol \% SiC Micro-Nanocomposites
}

\author{
Mira Jaafar ${ }^{1, *}$, Gilbert Fantozzi ${ }^{2}$ and Helen Reveron ${ }^{2}$ \\ 1 Laboratoire Matériaux, Catalyse, Environnement et Méthodes Analytiques (MCEMA), EDST, FS, \\ Université Libanaise, P.O. Box 11-2806, Campus Hariri, Hadath, Liban \\ 2 Insa-Lyon, MATEIS CNRS UMR 5510, Université de Lyon, 20 Av. Albert Einstein, \\ F-69621 Villeurbanne Cedex, France; gilbert.fantozzi@insa-lyon.fr (G.F.); helen.reveron@insa-lyon.fr (H.R.) \\ * Correspondence: mira.jaafar@hotmail.fr
}

Received: 11 April 2018; Accepted: 22 May 2018; Published: 24 May 2018

\begin{abstract}
Alumina/5 vol \% $\mathrm{SiC}$ micro-nanocomposites were produced by slip-casting and pressureless sintering. The dispersion of alumina and $\mathrm{SiC}$ particles in water using an electrosteric dispersant was studied for different solid contents. Although the rheological and granulometry measurements showed that the optimum amount of Darvan $C$ for well-dispersing $50 \mathrm{wt} \%$ dry matter slurries was $0.20 \mathrm{vol} \%$, this content was increased to $1.00 \mathrm{vol} \%$ in order to avoid the demixing of SiC nanoparticles during shaping. Well densified $(>99 \%)$ alumina-SiC pressureless sintered materials were obtained at $1800{ }^{\circ} \mathrm{C}-2 \mathrm{~h}$ in which $\mathrm{SiC}$ nanoparticles occupied inter/intragranular positions. The creep behaviour of these materials was examined at $1200^{\circ} \mathrm{C}$ under stresses ranging from 70 to $140 \mathrm{MPa}$. A good creep resistance in alumina-SiC materials was obtained demonstrating that the use of less expensive conventional sintering methods is possible and highlighting the importance of the dispersion step.
\end{abstract}

Keywords: composite materials; dispersion; pressureless sintering; microstructure; scanning electron microscopy (SEM); creep

\section{Introduction}

Following the first work of Niihara and his co-workers [1], ceramic nanocomposites have been extensively studied due to their excellent mechanical properties. The concept of nanocomposites, which involves the incorporation of some fine particles into a host matrix, has been applied successfully in many ceramic systems that have already developed better mechanical properties (strength, hardness, toughness and creep resistance). Two types of nanocomposite microstructures have been described by Niihara: (1) "nano-nano" or a dispersion of two nanophases and (2) "micro-nano" or a dispersion of fine inclusions into a micro-sized matrix.

Niihara and his co-workers revealed that the dispersion of $5 \mathrm{vol} \%$ nanometer-sized SiC particles into alumina matrix results in substantial improvement of the strength (up to $1 \mathrm{GPa}$ ) and an increase from 3.25 to $4.70 \mathrm{MPa} \sqrt{ } \mathrm{m}$ of the fracture toughness. Subsequently, many researchers have shown the good creep behavior of the alumina/SiC nanocomposites compared to pure monolithic alumina [2-5]. Nakahira et al. [5] carried out flexure creep experiments on an alumina/17 vol \% SiC nanocomposite and a monolithic alumina at $1100{ }^{\circ} \mathrm{C}$ to $1400{ }^{\circ} \mathrm{C}$ under a constant load of $100 \mathrm{MPa}$. They found that the creep rate of nanocomposites was four orders of magnitude lower than that of the monolithic. Ohji et al. [2] conducted tensile and flexure creep tests for alumina/SiC nanocomposites and monolithic alumina with the same alumina grain size in the temperature range of $1200-1300{ }^{\circ} \mathrm{C}$ and under stresses of 50-150 MPa. They revealed that the minimum creep rate of the nanocomposites was three orders of magnitude lower and the creep life was 10 times longer than that of monolithic alumina. Since then, 
worldwide researchers have been trying to optimize the microstructure of this type of materials, expecting an improvement in their performance. However, a homogeneous uniform microstructure can only be obtained if the starting suspension has high homogeneity and stability. Achieving adequate dispersion of ceramic powders is the primary requirement for suspension-based ceramic green forming and it is generally necessary to prepare suspensions with as high a solid content and as low a viscosity as possible. This homogeneity must be preserved during all the processing steps: particles dispersion, the shaping process (for example by slip-casting), drying, burning-out, and sintering.

Due to the wide use of alumina ceramics, the dispersion of these powders into water has been extensively studied and the dispersants used are commonly polyelectrolytes such as polyacrylic acid (PAA), polymethylacrylic acid (PMAA) and ammonium polymeric monomers [6-8]. So, for binary ceramic suspensions like alumina/SiC, the complex particulate interactions that determine the overall processing behaviour are difficult to quantify. The point of zero charge (PZC) of SiC lies in the range $\mathrm{pH} 2-4$, depending on the nature of the powder used [9,10], whilst that of $\mathrm{Al}_{2} \mathrm{O}_{3}$ is generally at $\mathrm{pH}$ 8-9 [11-13]. Mixing these two powders in aqueous media, therefore, causes heteroaggregation due to the electrostatic attraction of the differently charged particles.

Ceramic composites are usually obtained by hot pressing (HP) of a powder mixture. They can also be produced by the slip-casting technique from ceramic suspensions or by a cold isostatic pressing (CIP) followed by conventional sintering. Recently, the spark plasma sintering (SPS) process has attracted increasing interest as a new pressing sintering method for various kinds of materials $[14,15]$. The SPS process is very similar to hot pressing (HP) regarding the application of mechanical pressure during heating. In contrast to the HP where the heat is provided by external heating elements, in SPS the heat is generated by a pulsed electric current that passes directly through the graphite die and, in case of conductive samples, through the powder compact $[16,17]$.

In the present work, the possibility of obtaining dense and homogeneous micro-nano alumina $/ 5 \mathrm{vol} \% \mathrm{SiC}$ composites by slip-casting and pressureless sintering is demonstrated. The wet processing of nanocomposites here developed is based on the use of a polyelectrolyte as dispersant. The effect of the dispersant and dry matter content on the stability of slurries is investigated using rheological and granulometric measurements. It is clear that a compromise must be found between the slurry stability and the segregation of alumina-SiC particles by adjusting the amount of dispersant and dry matter content. Besides the production cost reduction related to the use of the conventional sintering method, the slip-casting technique avoids the step of drying which usually leads to the formation of less-pressable powders containing hard agglomerates. The use of slip-casting as a shaping method also allows the processing of complex shapes. The main purpose of this study is to recall that high green densities are absolutely needed in order to densify materials well via pressureless sintering, especially when facing second phase inclusions that will retard the densification. In particular, we show that high creep-resistant alumina/SiC materials can be obtained by slip-casting and pressureless sintering if the dispersion of slurries is well-controlled. A crucial research question of our work was, thus, how to re-coagulate slurries to avoid SiC demixing while keeping homogeneous dispersions and high green densities.

\section{Materials and Methods}

Alumina powder (CR1 from Baikowski, Poisy, France; $d_{50}=1 \mu \mathrm{m}$ ) with a very low amount of $\mathrm{Mg}(<1 \mathrm{ppm})$ was used as matrix raw material. In order to investigate the effect of the size of $\mathrm{SiC}$ into the creep behavior, two powders (UF25 from Starck, Selb, Germany; $d_{50}=450 \mathrm{~nm}$ and Marketech International, Port Townsend, WA, USA; $d_{50}=60 \mathrm{~nm}$ ) were selected as starting materials. Manufacturer's data of these materials are shown in Table 1. An ammonium salt of polymethacrylic acid ( $\mathrm{NH}_{4}$-PMAA) (Darvan C, $25 \mathrm{wt} \%$ aqueous solution) was used as an anionic dispersant and its amount was adjusted according to the dry wt $\%$ of alumina. Initially, to process alumina $/ 5 \mathrm{vol} \% \mathrm{SiC}$ micro-nanocomposites from homogeneous slurries, dispersion conditions were optimized. Slurries containing $5 \mathrm{vol} \%$ of $\mathrm{SiC}$ were ball-milled $48 \mathrm{~h}$ in distilled water using $\mathrm{Al}_{2} \mathrm{O}_{3}$ grinding media, solid 
loadings ranging from 50 to $70 \mathrm{wt} \%$ and Darvan C content from 0.06 to $1.00 \mathrm{vol} \%$. Subsequently, slurries were degassed under vacuum for few minutes and slip-casted over alumina plaster plates using PVC moulds $(70 \times 35 \times 15 \mathrm{~mm}$ in the case of materials for creep characterization or $20 \mathrm{~mm}$ in diameter-5 $\mathrm{mm}$ height for studying the sintering behaviour).

Table 1. Raw materials.

\begin{tabular}{|c|c|c|c|c|c|}
\hline Material & Phase (\%) & Purity (\%) & $\begin{array}{l}\text { Brunauer, Emmett and Teller } \\
\text { (BET) Particle Size }(\mathrm{nm})\end{array}$ & $\begin{array}{l}\text { Specific Surface } \\
\text { Area }\left(\mathrm{m}^{2} / \mathrm{g}\right)\end{array}$ & $d_{50}(\mu \mathrm{m})$ \\
\hline Alumina CR1 & $95 \% \alpha-5 \% \gamma-\mathrm{Al}_{2} \mathrm{O}_{3}$ & 99.9 & 457 & 3.3 & 0.60 \\
\hline SiC UF25 & $\alpha-\mathrm{SiC} 6 \mathrm{H} / 4 \mathrm{H}$ polytype & 98.0 & 78 & 24.5 & 0.45 \\
\hline SiC Marketech & $\alpha-\mathrm{SiC}$ & - & - & - & 0.06 \\
\hline
\end{tabular}

Slip-casted samples were then dried $\left(24 \mathrm{~h}\right.$ at ambient temperature then $48 \mathrm{~h}$ at $\left.50{ }^{\circ} \mathrm{C}\right)$ and sintered under argon in a conventional graphite furnace. During the thermal treatment, debinding was first performed under vacuum at $1{ }^{\circ} \mathrm{C} / \mathrm{min}$ up to $600{ }^{\circ} \mathrm{C}$ for $1 \mathrm{~h}$ followed by sintering under argon atmosphere at $10^{\circ} \mathrm{C} / \mathrm{min}$ up to 1800 or $1860^{\circ} \mathrm{C}$ for $2 \mathrm{~h}$. Green densities were estimated geometrically. Final bulk densities were determined by Archimedes' method using distilled water and three different weight measurements (dried mass, mass in water and mass embedded in water) according to the C373-88 ASTM standard test method. The relative density was obtained by correlating the bulk density with the theoretical density of an alumina $/ 5 \mathrm{vol} \% \mathrm{SiC}$ mixture. Microstructural features of sintered samples were examined on selected materials by scanning electron microscopy (SEM) (ESEM FEG XL-30, FEI, Hillsboro, OR, USA) on polished and thermally etched surfaces $\left(1400{ }^{\circ} \mathrm{C}\right.$ for 20 or $45 \mathrm{~min}$, under argon). Grain size was estimated by means of the linear intercept method, from at least 500 grains counts without using any multiplying factor. As discussed later, the use of SiC Marketech on the development of creep-resistant composites was compromised because of its poor sinterability through conventional sintering. Nevertheless, we deem necessary to report here the attempts we made to disperse this new powder in order to show the limitations encountered.

To study the suspension rheological behavior, a viscometer fitted with a concentric cylinder measuring head was used (Haake Rotovisco RV-12, Malvern Instruments, Worcrstershire, United Kingdom). $\mathrm{NaOH}$ and $\mathrm{HCl}$ were used to adjust the $\mathrm{pH}$ of suspensions. A given quantity of the slurry was placed into the viscosimeter and the cylinder resistance to rotation was measured. The shear rate was scanned from zero to $1500 \mathrm{~s}^{-1}$ in $2 \mathrm{~min}$ and, after a dwell of $1 \mathrm{~min}$, the scan was realized from $1500 \mathrm{~s}^{-1}$ to zero. Granulometric measurements were taken in water using a laser system apparatus (Mastersizer 2000, Malvern Instruments, Worcrstershire, United Kingdom ) equipped with a liquid sample unit (MS 519, Malvern Instruments, Worcrstershire, United Kingdom), from some slurry drops. The zeta potential of particles was determined by the electrophoretic method, using an apparatus with a quartz cell (Zetasizer Nano-ZS, Malvern Instruments, Worcrstershire, United Kingdom).

Creep tests were carried out in air in a 4-point-bending fixture at $1200{ }^{\circ} \mathrm{C}$ under stresses ranging from 70 to $140 \mathrm{MPa}$ using a testing machine developed in our laboratory. Specimens were parallelepipeds with the following dimensions: $b$ (sample width) $4 \mathrm{~mm}, w$ (sample height) $3 \mathrm{~mm}$ and $l$ (sample length) $40 \mathrm{~mm}$. The tensile faces were polished with diamond paste down to $3 \mu \mathrm{m}$ and the edges were chamfered (about $45^{\circ}$ ). The 4-point bending fixture made of alumina has an outer and inner span of $L=36 \mathrm{~mm}$ and $L^{\prime}=18 \mathrm{~mm}$ respectively. During the test, the deflection at the center of the sample was measured with a LVDT sensor (linear variable differential transformer, precision of $1 \mu \mathrm{m})$. The flexural stress on the tensile face was calculated by using the following expression:

$$
\sigma=\frac{3 P\left(L-L^{\prime}\right)}{2 b w^{2}}
$$

where $P$ is the applied load, $L$ the outer span, $L^{\prime}$ the inner span, $b$ the sample width, and $w$ the sample height. 
The creep strain $\varepsilon$ was calculated from the deflection $y$ at the center of the specimen, assuming no major cracking in the specimen as proposed by Hollenberg et al. [18]:

$$
\varepsilon=K(n) y
$$

with

$$
K(n)=\frac{2 w(n+2)}{\left(L-L^{\prime}\right)\left[L+L^{\prime}(n+1)\right]+L^{\prime 2}(n+2) / 2}
$$

and $n$ the stress exponent.

Furthermore, the steady-state creep rate can be expressed by the following equation:

$$
\dot{\varepsilon}=A \frac{\sigma^{n}}{d^{p}} \exp \left(-\frac{Q}{R T}\right)
$$

where $A$ is a material constant, $\sigma$ the applied stress, $d$ the grain size, $p$ the grain size exponent, $Q$ the activation energy for creep, $R$ the gas constant and $T$ the absolute temperature.

From the $K(n)$ expression (Equation (3)), it is clear that this constant depends on $n$ but also on the outer and inner span. Nevertheless, when $L / L^{\prime}$ is close to $2, K(n)$ becomes almost insensitive to the $n$ value. In this manner the creep strain $\varepsilon$ can be calculated from Equations (2) and (3) with a supposed $n$ value. If the determined and experimental $\varepsilon$ values are too different, calculations are realized again by setting another $n$ value and so on. The creep exponent $n$ was evaluated in a steady-state creep region from the slope of the straight line obtained when plotting the strain rate $(\dot{\varepsilon})$ versus the flexural stress $(\sigma)$ on a log-log plot.

\section{Results and Discussion}

\subsection{Alumina and SiC Powders Dispersion}

The first part of this study aimed to establish the best dispersion conditions with the purpose of produce aqueous slurries for slip-casting. In order to identify the most promising processing procedure, powders were characterized and the possibility of applying a purely electrostatic dispersion rejected. The effect of using a dispersant and slightly destabilizing systems was studied and discussed below.

\subsubsection{Determination of the Isoelectric Point (IEP) and the Effect of Darvan C}

Figure 1 shows zeta potential evolution of alumina CR1, SiC UF25 and SiC Marketech powders as a function of $\mathrm{pH}$. For alumina powder and, as expected, the IEP was located near $\mathrm{pH} 8$. Moreover, this powder could be dispersed electrostatically, without adding a dispersant, at very acidic or basic conditions since high values of the zeta potential were obtained $(>30 \mathrm{mV}$ for a pH between 4 and 6 or $<-30 \mathrm{mV}$ above 9.5). For SiC powders, IEPs were located at pHs of 3.2 (UF25) and 5.3 (Marketech) and surface charges were $<-30 \mathrm{mV}$ for $\mathrm{pH}$ values above 5.5 (UF25) or 6.5 (Marketech). The magnitude of the zeta potential is directly related to the magnitude of repulsive forces. For small zeta potentials the repulsive force is small, such that overall the van der Waals attractive force dominates and so aggregates form. However, with larger zeta potentials the repulsive force between particles is larger than the van der Waals attractive force, hence preventing particles from aggregation. These results indicate that in the absence of dispersants, our binary powder systems (alumina/SiC) could be dispersed at $\mathrm{pH}>9.5$, since measured zeta potentials were high.

Nevertheless, as for zeta potential measurements slurries were highly diluted, a different behavior can be obtained in non-diluted systems ( $>50 \mathrm{wt} \%$ dry matter). For this reason, the behavior of the slurry main constituent (alumina) was corroborated by means of viscosity measurements performed on alumina $50 \mathrm{wt} \%$ dry matter suspensions, ball-milled for $48 \mathrm{~h}$ in distilled water. 


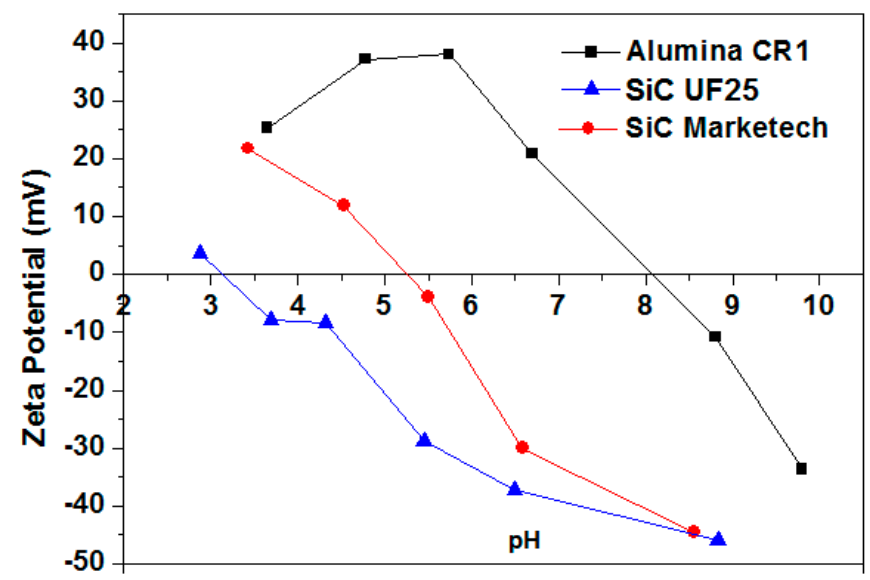

Figure 1. Zeta potential of alumina CR1, SiC UF25 and SiC Marketech.

Figure 2 shows the variation of the apparent viscosity of alumina slurries prepared at different $\mathrm{pH}$ for a shear rate of $300 \mathrm{~s}^{-1}$, without and with Darvan C. In the first case, the viscosity reaches a maximum towards a $\mathrm{pH}$ of 9 , validating the value close to 8 (IEP $\sim 8$ ) found from zeta potential measurements. For $\mathrm{pH}$ values below and above 8.8 , the viscosity of the slurries decreases, indicating that particles are increasingly well dispersed thanks to the surface charges. From these results, the true IEP of CR1 concentrated alumina suspensions (50 wt \% dry matter) is located near 9. Indeed, the high viscosity indicates that particles flocculate at this point [19].

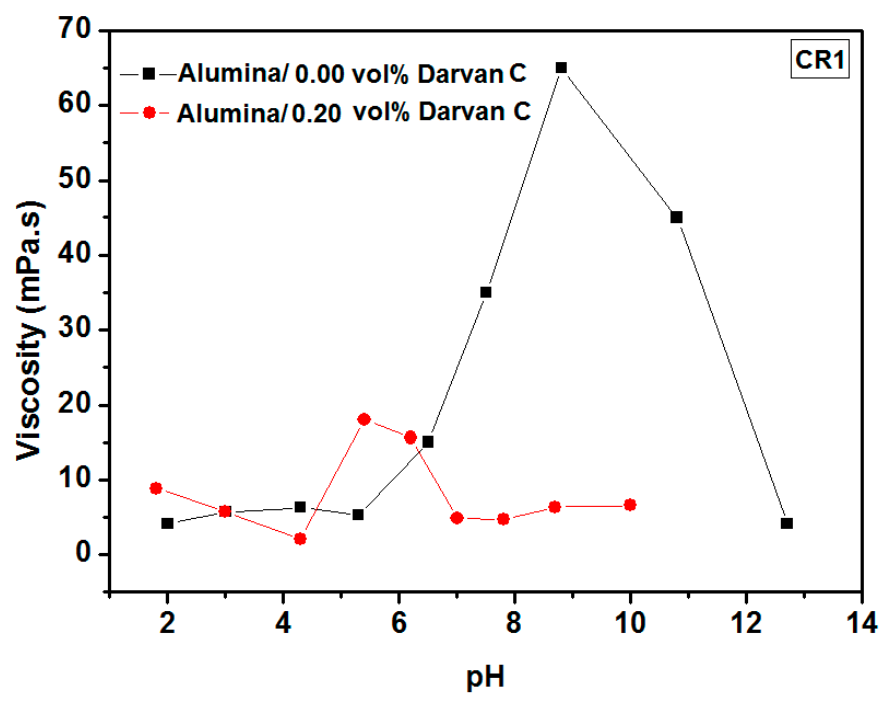

Figure 2. Apparent viscosity as function of $\mathrm{pH}$ for $50 \mathrm{wt} \%$ dry matter alumina CR1 slurries without and with Darvan C.

A common problem of applying pure electrostatic stabilization when dispersing two different materials is the difficulty of finding a $\mathrm{pH}$ range where both powder surfaces develop important charges of the same sign. Consequently, a dispersant is often added to suspensions especially if they contain very fine particles [12].

The second curve in Figure 2 reveals the shift of the IEP to the acidic $\mathrm{pH}$ range ( $\sim 9.0$ to 5.5) when using a dispersant [20]. The IEP diminution is related to the Darvan C adsorption at the surface of particles, which gives to them a more negative charge [21]. As a result, the more negatively charged surfaces require a larger number of $\mathrm{H}^{+}$ions to neutralize the charge and the IEP will shift to the acidic region [22] and stabilize at a given $\mathrm{pH}$ value [21]. Regarding $\mathrm{SiC}$ powders, several studies have shown 
that the interaction of $\mathrm{SiC}$ particles with polyelectrolytes also decreases the IEP [21]. In this study we did not characterized the influence of adding Darvan C on the IEP of SiC powders but we can expect a better dispersability because of an IEP shift to $\mathrm{pH}$ values below 3.2 (SiC UF25) or 5.3 (SiC Marketech). Considering the aforementioned results, we decided to disperse our suspensions at a $\mathrm{pH}$ of 9 which was the natural $\mathrm{pH}$ developed in slurries containing Darvan $\mathrm{C}$ without adding $\mathrm{NaOH}$. This value of 9 in the presence of Darvan $\mathrm{C}$ allows dispersing at a $\mathrm{pH}$ far from the IEPs of both powders that is 5.5 for alumina and well below 3.2 or 5.3 for SiCs UF25 and Marketeck, respectively.

\subsubsection{Optimization of the Dispersion Conditions}

During the preparation of the slurries by ball-milling, several parameters must be optimized. In our study, only the most critical were considered, namely (a) the amount of dispersant and (b) the solid content. In order to determine the optimal amount of Darvan C, viscosity measurements were carried out on slurries with $50 \mathrm{wt} \%$ dry matter and $5 \mathrm{vol} \%$ of SiC (UF25 or Marketech) containing different amounts of dispersant (in the range 0.06 to $1.00 \mathrm{vol} \%$ ). Prior viscosity measurement, slurries were homogenized for $48 \mathrm{~h}$ ( $23 \mathrm{~h}$ only with alumina $+25 \mathrm{~h}$ after $\mathrm{SiC}$ addition). Figure 3 shows the evolution of the viscosity of alumina-SiC UF25 and Marketech slurries as a function of the shear rate for different concentrations of Darvan C. As expected, the amount of Darvan $C$ has a direct influence on the viscosity, then on dispersing powders. The minimum viscosity was obtained for $0.20 \mathrm{vol} \%$ of Darvan C and the maximum for $0.06 \mathrm{vol} \%$. Beyond $0.20 \mathrm{vol} \%$ of dispersant, an increase in the viscosity indicates that, regardless of the nature of the SiC powder used in this study (Starck UF25 or Marketech), $0.20 \mathrm{vol} \%$ of Darvan C seems to be the optimum amount of dispersant [20].
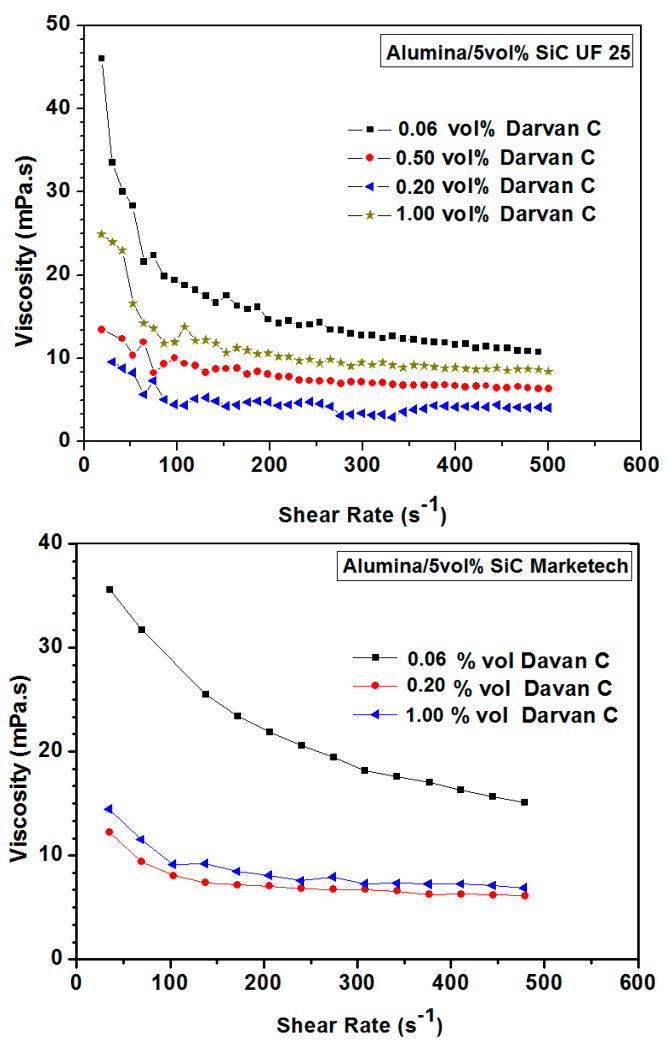

Figure 3. Evolution of the viscosity of $50 \mathrm{wt} \%$ dry matter alumina/SiC UF25 and alumina/SiC Marketech suspensions with the addition of Darvan C.

The particle size distributions (PSD), obtained in slips prepared using different amounts of Darvan $\mathrm{C}$ are displayed in Figure 4. These figures corroborate the fact that a concentration of $0.06 \mathrm{vol} \%$ of Darvan $\mathrm{C}$ is not sufficient to disperse the powders well. Whatever the $\mathrm{SiC}$ employed, distributions 
for $0.06 \mathrm{vol} \%$ of dispersant were centered near $1.5 \mu \mathrm{m}$ whereas from $0.20 \mathrm{vol} \%$ the main peak was centered around $1 \mu \mathrm{m}$. At this stage, in the two slurries (alumina/SiC UF25 or Marketech) a second peak in the PSD appeared near $150 \mathrm{~nm}$, giving a bimodal PSD which can be related with the dispersed $\mathrm{SiC}$ particles. The addition of more than $0.20 \mathrm{vol} \%$ Darvan $\mathrm{C}$ did not improve the dispersion and promoted reagglomeration of fine particles in the case of $\mathrm{SiC}$ Marketech (the distribution became monomodal at $1.00 \mathrm{vol} \%$ of dispersant).
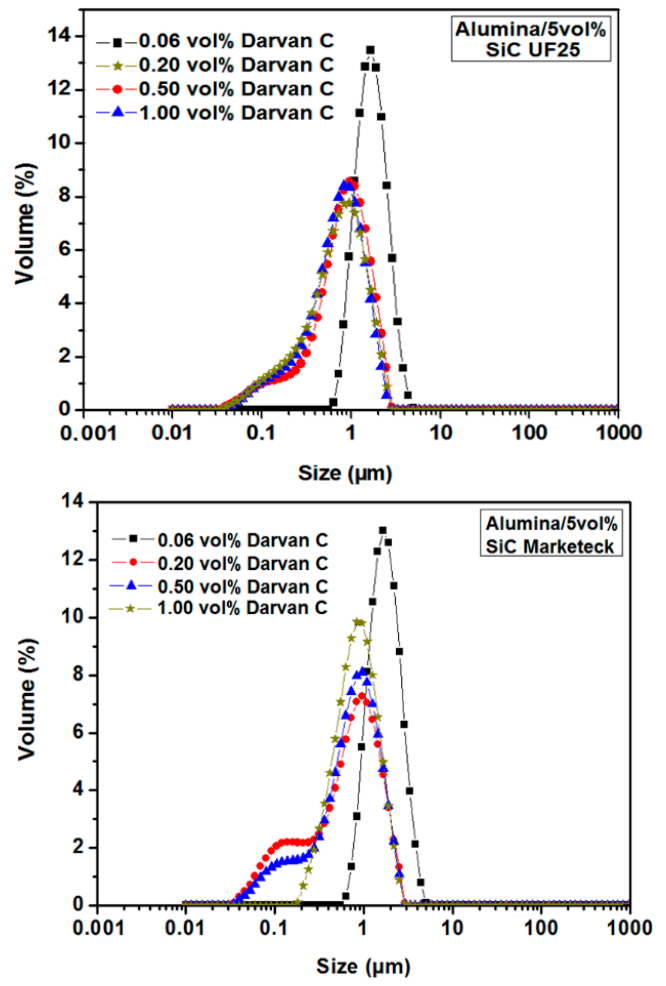

Figure 4. Particle size evolution of alumina $/ 5 \mathrm{vol} \% \mathrm{SiC}$ ( $50 \mathrm{wt} \%$ dry matter) suspensions with different amounts of Darvan C.

The good dispersion of SiC particles into the slurries was also confirmed by SEM from suspension drops which were deposited and dried on the sample holder. The SEM image of Figure 5 shows an example of a photomicrograph in the case of alumina/5 vol \% SiC UF 25 system $(0.20 \mathrm{vol} \%$ of Darvan C, $50 \mathrm{wt} \%$ dry matter, $48 \mathrm{~h}$ of ball-milling). SiC particles uniformly distributed within the matrix of alumina particles were observed. The same behavior was observed in alumina/SiC Marketech suspensions.
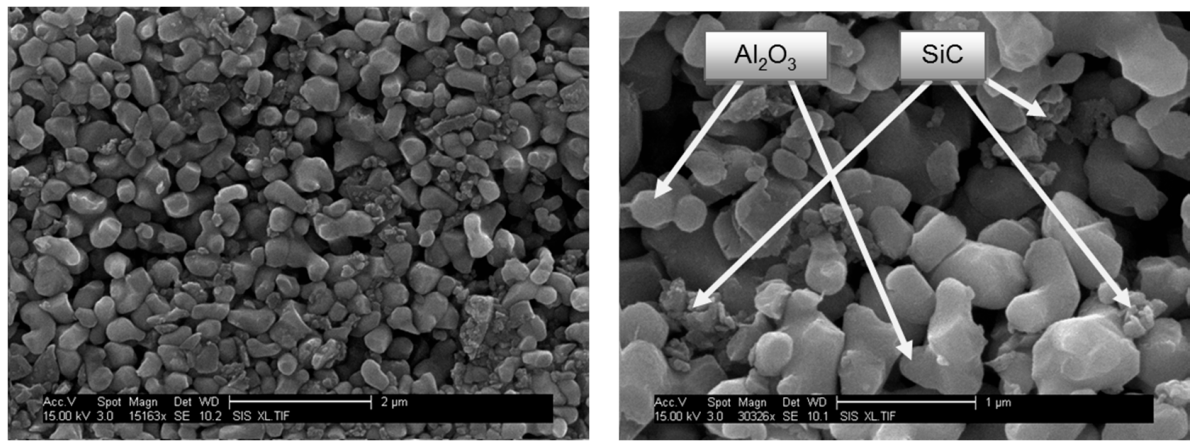

Figure 5. Scanning electron microscopes (SEM) micrographs of $50 \mathrm{wt} \%$ dry matter alumina/5 vol \% SiC UF25 slurry dispersed in the presence of 0.20 vol \% of Darvan C. 
The effect of the dry matter content on the rheological behavior and PSD of the alumina/SiC suspensions was only studied in alumina/SiC UF25 containing $1.00 \mathrm{vol} \%$ of Darvan C. Considering the very similar results obtained for the two $\mathrm{SiC}$ powders during the viscosity and PSD characterizations just showed above (50 wt \% of dry matter), we can expect similar trends concerning the variation of viscosity with the quantity of suspended solids. Figure 6 shows the evolution of the viscosity as a function of the shear rate of three slurries containing 50,60 and $70 \mathrm{wt} \%$ dry matter. This figure demonstrates that the viscosity increases with the amount of dry matter since the distance between particles decreases. To be used in the production of a green body through the slip-casting method, the slurry must have a viscosity of less than $60 \mathrm{mPa} \cdot \mathrm{s}$ at low shear rate. If the viscosity at low shear rate (corresponding to the state of rest during casting) is too high, the suspension can destabilize at the beginning of setting and flocculate. This would result in a different sedimentation rate between the bottom and the top of the casting [23] and, consequently, in non-homogeneous green bodies. This was the case for slips with solid contents of 60 and $70 \mathrm{wt} \%$ (1.00 vol \% of Darvan C), hence the value of $50 \mathrm{wt} \%$ dry matter was selected for developing ceramics to be used in creep tests.

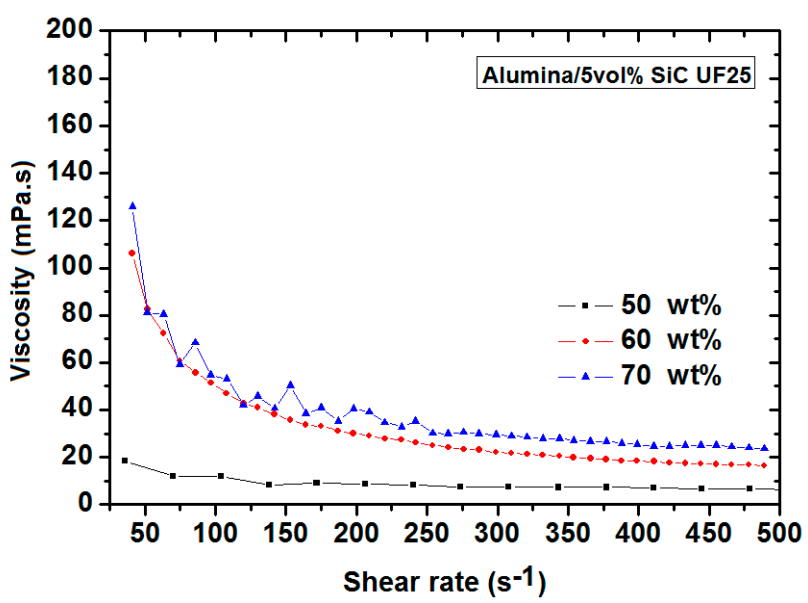

Figure 6. Evolution of the viscosity of alumina $/ 5$ vol \% SiC UF25 suspensions ( 1.00 vol \% of Darvan C) containing different amounts of dry matter.

It should be emphasized here that an amount of dispersant above the optimum value $(0.20 \mathrm{vol} \%)$ was selected in order to slightly coagulate the system. In fact, it is well known that as the amount of dispersant in excess cannot be attached to the surface of particles, it remains in the aqueous phase. This non-adsorbed polyelectrolyte would disturb the electrostatic forces and lead to a phenomenon of particle coagulation and, as a consequence, to an increase of the viscosity [22]. As we are processing ceramics through slip-casting, the amount of dispersant was increased to avoid the segregation of alumina and $\mathrm{SiC}$ particles. Thereby, for processing ceramics for creep tests, we used $1.00 \mathrm{vol} \%$ of Darvan C instead of $0.20 \mathrm{vol} \%$. In this manner, we were able to produce very homogenous ceramics without compositional gradients along the direction of slip-casting.

\subsection{Conventional Sinstering of Alumina/SiC Composites}

Preliminary sintering experiments performed on all alumina $/ 5 \mathrm{vol} \% \mathrm{SiC}$ systems described in the previous section showed that it was impossible to densify composites well using conventional sintering when the finer $\mathrm{SiC}$ powder (Marketech) was used. This behavior can be related to the very fine size of $\mathrm{SiC}$ particles $(60 \mathrm{~nm})$ since densification is hindered by the extremely large number of nanoparticles located at the alumina grain boundaries. For this reason and due to the fact that creep analysis requires samples with high density, the use of $\mathrm{SiC}$ Marketech was stopped at this point of the study. The results obtained on alumina/ 5 vol \% SiC UF 25 micro-nanocomposites and summarized in Table 2 show the effect of the dispersion conditions on the densification and the microstructure. 
Table 2. Density and matrix grain size of different alumina/5 vol \% SiC UF25 micro-nanocomposites.

\begin{tabular}{|c|c|c|c|c|c|c|}
\hline Sample & $\begin{array}{l}\text { Solid Loading } \\
\text { (wt \%) }\end{array}$ & $\begin{array}{c}\text { Darvan C } \\
\text { (vol \%) }\end{array}$ & $\begin{array}{c}\text { Sintering } \\
\text { Temperature }\left({ }^{\circ} \mathrm{C}\right)\end{array}$ & $\begin{array}{c}\text { Green Density } \\
\text { (\%td) }\end{array}$ & $\begin{array}{c}\text { Final Density } \\
\text { (\%td) }\end{array}$ & $\mathrm{d}_{\text {mean }}(\mu \mathrm{m})$ \\
\hline 1 & 50 & 1.00 & 1800 & 60 & 99.1 & $3.7 \pm 1.5$ \\
\hline 2 & 60 & 1.00 & 1800 & 58 & 94.1 & $2.5 \pm 1.1$ \\
\hline 3 & 70 & 1.00 & 1800 & 57 & 90.0 & $1.9 \pm 0.7$ \\
\hline 4 & 50 & 0.06 & 1800 & 45 & 88.0 & $2.5 \pm 0.8$ \\
\hline 5 & 50 & 0.50 & 1800 & 60 & 99.1 & $3.9 \pm 1.7$ \\
\hline 6 & 50 & 1.00 & 1860 & 60 & 99.3 & $4.4 \pm 2.2$ \\
\hline 7 & 60 & 1.00 & 1860 & 58 & 99.2 & - \\
\hline 8 & 70 & 1.00 & 1860 & 57 & 97.7 & - \\
\hline 9 & 50 & 0.50 & 1860 & 60 & 99.3 & $4.5 \pm 2.2$ \\
\hline
\end{tabular}

With regard to the densities obtained after shaping and sintering, it is observed that the state of dispersion influenced the final characteristics of sintered samples highly as follows:

- Increasing the percentage of dry matter beyond $50 \mathrm{wt} \%$ promoted a decrease in the green density and consequently in the final density of samples.

- The amount of Darvan C had a direct influence on the densities reached before and after sintering. Samples obtained from well-dispersed suspensions ( 0.50 or 1.00 vol \% Darvan C) exhibited higher densities than samples obtained from poorly dispersed suspensions (0.06 vol \% Darvan C).

- In addition, increasing the sintering temperature resulted in higher final density and alumina grain size, especially in materials processed from 60 and $70 \mathrm{wt} \%$ dry matter slurries.

In the remainder of this article, the following notation will be used:

$\mathrm{DM}_{50,60 \text { or } 70} \mathrm{DC}_{0.06,0.5 \text { or } 1}$ where:

DM: Dry matter 50, 60 or $70 \mathrm{wt} \%$

DC: Darvan C 0.06, 0.50 or 1.00 vol \%

The microstructures obtained on some selected pressureless sintered materials are shown in Figure 7. For a sintering temperature of $1800^{\circ} \mathrm{C}$, very dense materials were prepared from suspensions dispersed using optimized processing conditions $\left(\mathrm{DM}_{50} \mathrm{DC}_{1}\right.$, Figure $\left.7 \mathrm{a}\right)$ or even at lower Darvan $\mathrm{C}$ concentration ( $\mathrm{MS}_{50} \mathrm{DC}_{0.5}$, Figure $7 \mathrm{~d}$ ). The relatively low densification of samples $\mathrm{DM}_{60} \mathrm{DC}_{1}, \mathrm{MS}_{70} \mathrm{DC}_{1}$ or $\mathrm{DM}_{50} \mathrm{DC}_{0.06}$ (see Table 2) is corroborated by the presence of a considerable amount of pores as observed in Figure $7 \mathrm{~b}-\mathrm{e}$, respectively). The effect of increasing the sintering temperature by $60{ }^{\circ} \mathrm{C}$ is almost imperceptible, only alumina grain sizes changed from $d_{\text {mean }}=3.7 \pm 1.5$ to $4.4 \pm 2.2 \mu \mathrm{m}$ $\left(\mathrm{DM}_{50} \mathrm{DC}_{1}\right.$, Figure $7 \mathrm{a}, \mathrm{f}$, respectively).

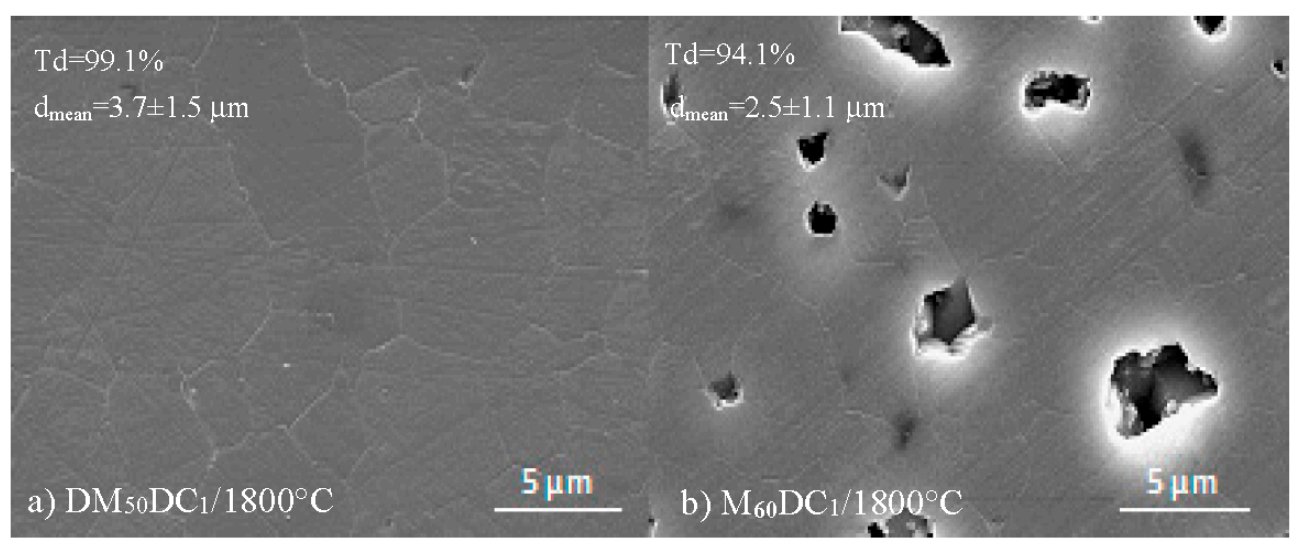

Figure 7. Cont. 

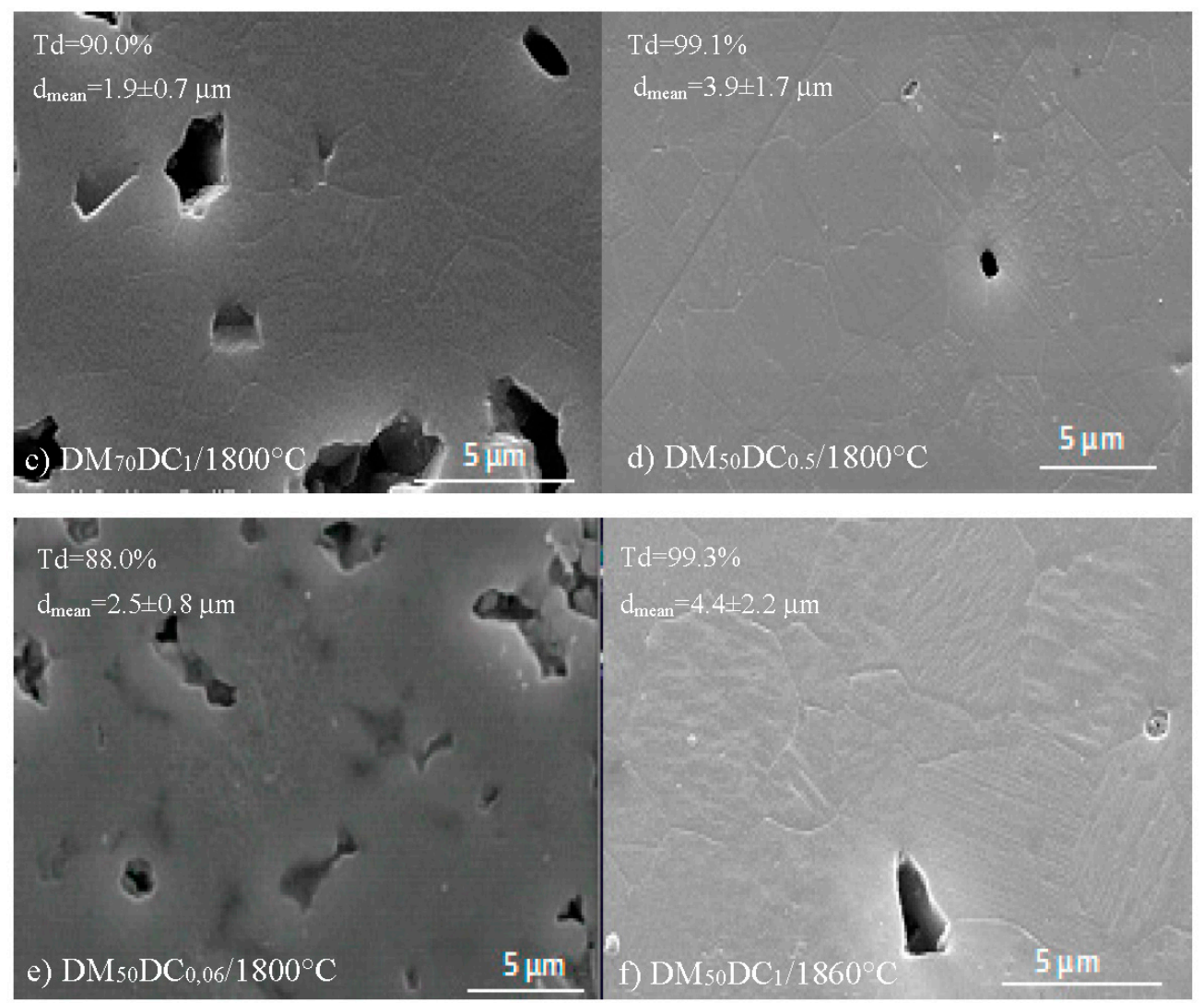

Figure 7. SEM microstructures of the alumina/SiC UF25 micro-nanocomposites obtained from suspensions with different amounts of dry matter and Darvan $\mathrm{C}$ and sintered at $1800{ }^{\circ} \mathrm{C}-2 \mathrm{~h}(\mathbf{a}-\mathbf{e})$ and $1860{ }^{\circ} \mathrm{C}-2 \mathrm{~h}(\mathbf{f})$.

A closer microstructural observation shows that materials developed by conventional sintering were of the inter-intragranular type, with $\mathrm{SiC}$ particles located at the grain boundaries and inside alumina grains (Figure 8).

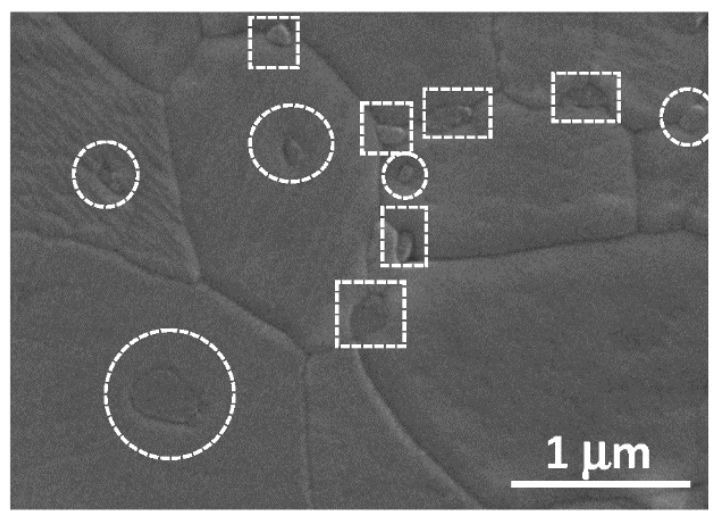

Figure 8. SEM microstructural characterization of micro-nanocomposites of alumina $/ 5 \mathrm{vol} \% \mathrm{SiC}$ UF25 showing SiC particles along (dashed-squares) and inside alumina grains (dashed-circles).

\subsection{Creep Behaviour}

For creep analysis, composites were prepared using the optimized processing conditions $\left(\mathrm{DM}_{50} \mathrm{DC}_{1}\right)$ and sintered conventionally at $1800{ }^{\circ} \mathrm{C}-2 \mathrm{~h}$. These ceramics were characterized by a final density $>\sim 99 \%$, alumina grain size of $\mathrm{d}_{\text {mean }}=3.7 \pm 1.5 \mu \mathrm{m}$ and $\mathrm{SiC}$ grain sizes ranging from $\sim 0.1$ to $\sim 0.5 \mu \mathrm{m}$. 
Figure 9 shows creep results obtained at $1200{ }^{\circ} \mathrm{C}$ in the stress range $70-140 \mathrm{MPa}$. The curves exhibit only primary creep and steady-state creep regions (no tertiary creep region was observed). Moreover, samples were not fractured after $60 \mathrm{~h}$ of test. The evolution of the strain rate over time shows that after about $40 \mathrm{~h}$, the strain rate became approximately constant. This allowed us to define a stationary rate of deformation.

Table 3 summarizes different strain and strain rate after $60 \mathrm{~h}$ of test. As expected, deformations and creep rates increased with the stress.
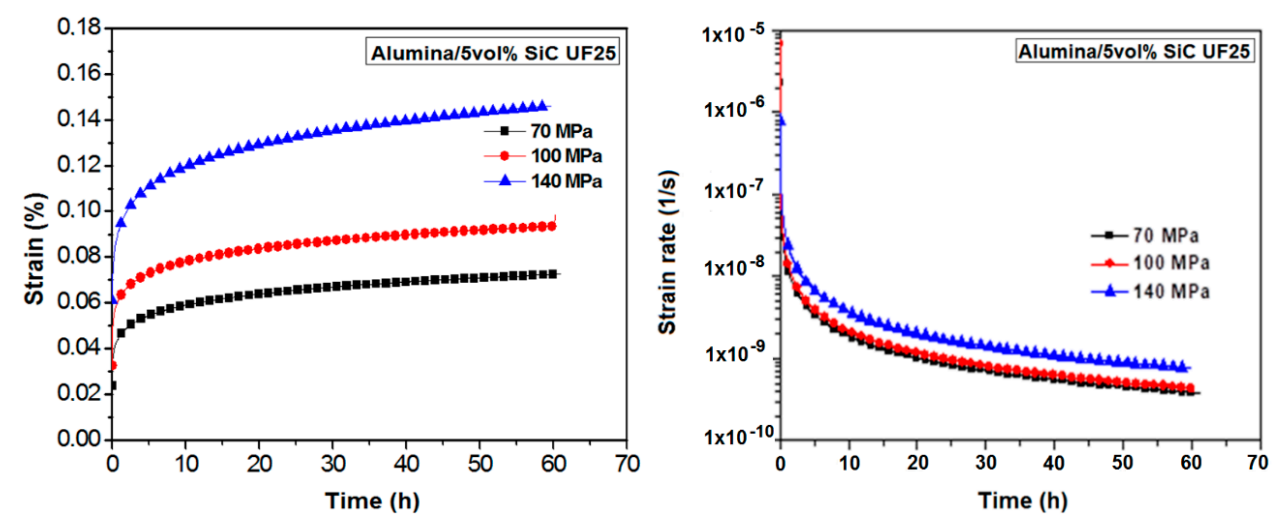

Figure 9. Creep strain and strain rate of alumina $/ 5$ vol \% SiC UF25 $\left(\mathrm{DM}_{50} \mathrm{DC}_{1}-1800{ }^{\circ} \mathrm{C}-2 \mathrm{~h}\right)$.

Table 3. Creep results of Alumina $/ 5$ vol \% SiC $\left(\mathrm{DM}_{50} \mathrm{DC}_{1}-1800{ }^{\circ} \mathrm{C}-2 \mathrm{~h}\right)$ after $60 \mathrm{~h}$ of test experiment at $1200{ }^{\circ} \mathrm{C}$.

\begin{tabular}{ccc}
\hline $\boldsymbol{\sigma} \mathbf{( M P a )}$ & Strain (\%) & Strain Rate (1/s) \\
\hline $\mathbf{7 0}$ & 0.07 & $4.0 \times 10^{-10}$ \\
$\mathbf{1 0 0}$ & 0.09 & $4.3 \times 10^{-10}$ \\
$\mathbf{1 4 0}$ & 0.15 & $7.5 \times 10^{-10}$ \\
\hline
\end{tabular}

The stress exponent $n$, calculated from steady-state creep rates obtained after $60 \mathrm{~h}$ was close to the unit $(n=1.2$, see Figure 10), suggesting that the creep was controlled by a diffusional mechanism either at the grain boundaries (Coble diffusion) or in the matrix (Nabarro-Herring diffusion) associated with a creep sliding mechanism at the grain boundaries [24].

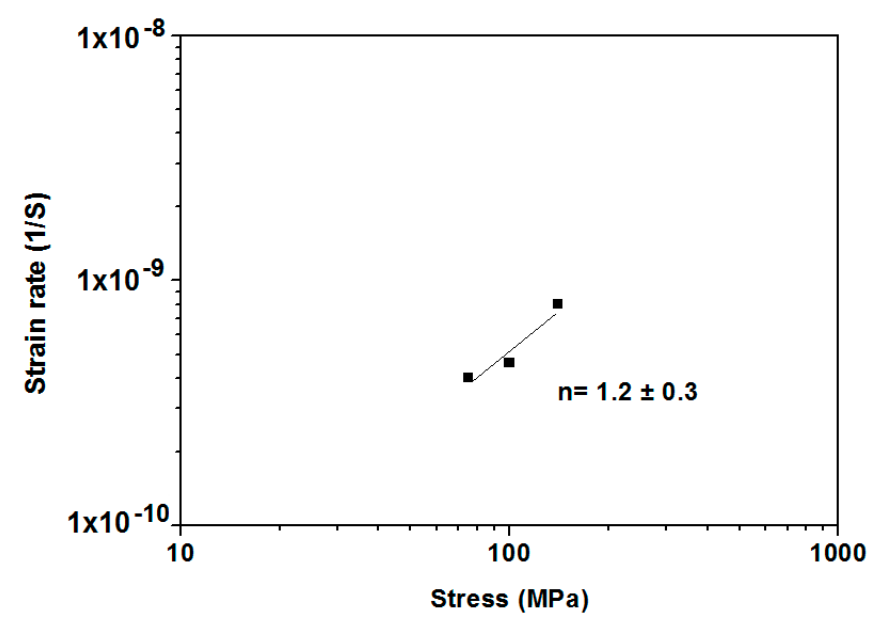

Figure 10. Stress exponent of alumina $/ 5$ vol \% SiC $\left(\mathrm{DM}_{50} \mathrm{DC}_{1}-1800{ }^{\circ} \mathrm{C}-2 \mathrm{~h}\right)$. 
It should be noted that compared to previous creep rates already reported on hot-pressed alumina $/ 5$ vol \% SiC materials $[3,4,25]$ comparable values were obtained here. The highest steady-state creep rate of $1 \times 10^{-10} \mathrm{~s}^{-1}$ for alumina/SiC composites has been obtained in hot-pressed alumina/ $17 \mathrm{vol} \%$ $\mathrm{SiC}$ composites tested at $1200^{\circ} \mathrm{C}$ under $100 \mathrm{MPa}$ (see Table 4) [2]. As in our samples, these composites exhibited inter/intragranular $\mathrm{SiC}$ positioning but, surprisingly, our fabricated materials which contained a lower quantity of $\mathrm{SiC}$ and were conventionally sintered also showed excellent creep resistance.

Table 4. Steady-state creep rates for alumina/SiC composites $\left(1200{ }^{\circ} \mathrm{C}-100 \mathrm{MPa}\right)$.

\begin{tabular}{ccc}
\hline Sample & Grain Size $(\boldsymbol{\mu m})$ & Strain Rate (1/s) \\
\hline Alumina/5 vol \% SiC UF25 (this work) & $3.7 \pm 1.5$ & $4.3 \times 10^{-10}$ \\
Alumina/17 vol \% SiC (Ohji et al. [2]) & 2.0 & $1.0 \times 10^{-10}$ \\
\hline
\end{tabular}

\section{Conclusions}

Effective stabilization of alumina $/ 5 \mathrm{vol} \% \mathrm{SiC}$ slurries was carried out using an ammonium salt of polymetacrylic acid (Darvan C) as anionic dispersant. The IEP shifted to the acidic $\mathrm{pH}$ range on alumina-polyelectrolyte and $\mathrm{SiC}$-polyelectrolyte aqueous suspensions when $0.20 \mathrm{vol} \%$ of Darvan C was added. This shift allowed the stabilization of alumina $/ 5 \mathrm{vol} \% \mathrm{SiC}$ slurries at the natural $\mathrm{pH}$ of 9 , avoiding in this manner the use of additional base or acid for adjusting the $\mathrm{pH}$. Moreover, the study of the Darvan C amount and the dry matter content on the stabilization of alumina $/ 5 \mathrm{vol} \% \mathrm{SiC}$ suspensions demonstrated that $0.20 \mathrm{vol} \%$ of Darvan C with $50 \mathrm{wt} \%$ of dry matter were the optimized conditions to obtain well-dispersed slurries. Nevertheless, a dispersant content increase up to $1.00 \mathrm{vol} \%$ of Darvan C was necessary to develop homogeneous alumina / 5 vol \% SiC composites by slip-casting. Increasing the dispersant concentration allowed preparing slurries with higher viscosity that prevented $\mathrm{SiC}$ particle segregation during the shaping process. The sintering and creep results presented here demonstrate that it is possible to use inexpensive techniques such as slip-casting and pressureless sintering in the development of highly dense and creep-resistant alumina/SiC micro-nanocomposites. Nevertheless, if very fine $\mathrm{SiC}$ particles are employed or if the quantity of $\mathrm{SiC}$ is too high, the use of pressureless sintering seems to be compromised.

Author Contributions: G.F., H.R. and M.J. conceived and designed the experiments; M.J. performed the experiments; M.J., H.R. and G.F. analyzed the data; M.J. and H.R. wrote the paper.

Funding: This research was funded by the European Commission (IP Nanoker NMP3-CT-2005-515784).

Acknowledgments: Financial support for this project by the European Commission is gratefully acknowledged (IP Nanoker P3-CT-2005-515784).

Conflicts of Interest: The authors declare no conflict of interest. The funding sponsors had no role in the design of the study; in the collection, analyses, or interpretation of data; in the writing of the manuscript, and in the decision to publish the results.

\section{References}

1. Niihara, K. New Design Concept of Structural Ceramics-Ceramic Nanocomposites. J. Ceram. Soc. Jpn. 1991, 99, 974-982. [CrossRef]

2. Ohji, T.; Nakahira, A.; Hirano, T.; Niihara, K. Tensile Creep Behavior of Alumina/Silicon Carbide Nanocomposite. J. Am. Ceram. Soc. 1994, 77, 3259-3262. [CrossRef]

3. Descamps, A.; O'Sullivan, D.; Poorteman, M.; Descamps, J.C.; Leriche, A.; Cambier, F. Creep behaviour of Al2O3-SiC Nanocomposites. J. Eur. Ceram. Soc. 1999, 99, 2475-2485. [CrossRef]

4. Thompson, A.M.; Chan, H.M.; Harmer, M.P. Tensile Creep of Alumina-Silicon Carbide Nanocomposites. J. Am. Ceram. Soc. 1997, 80, 2221-2228. [CrossRef]

5. Nakahira, A.; Niihara, K. Microstructure and High-Temperature Mechanical Properties for $\mathrm{Al} 2 \mathrm{O} 3 / \mathrm{SiC}$ Nanocomposites. In Proceedings of the 95th Annual Meeting of the American Ceramic Society, Cincinnati, OH, USA, 18-22 April 1993. 
6. Hackley, V.A. Colloidal processing of silicon nitride with poly(acrylic acid). I. adsorption and electrostatic interactions. J. Am. Ceram. Soc. 1997, 80, 2315-2325. [CrossRef]

7. Dupont, L.; Foissy, A. Evaluation of the adsorption trends of a low molecular weight polyelectrolyte with a site-binding model. Colloid Surf. A Physicochem. Eng. Aspects 1996, 110, 235-248. [CrossRef]

8. Hidber, P.C.; Graule, T.J.; Gauckler, L.J. Citric acid-A dispersant for aqueous alumina suspensions. J. Am. Ceram. Soc. 1996, 79, 1857-1867. [CrossRef]

9. Adair, H.J.; Mutsuddy, B.C.; Drauglis, E.J. Stabilization of silicon carbide whisker suspensions: I, Influence of surface oxidation in aqueous suspensions. Adv. Ceram. Mater. 1988, 3, 231-234. [CrossRef]

10. Whitman, P.K.; Feke, D.L. Colloidal characterization of ultrafine silicon carbide and silicon nitride powders. Adv. Ceram. Mater. 1986, 1, 366-370. [CrossRef]

11. Cesarano, J., III; Aksay, I.A. Processing of highly concentrated aqueous alumina suspensions stabilized with polyelectrolytes. J. Am. Ceram. Soc. 1988, 71, 1062-1067. [CrossRef]

12. Cesarano, J., III; Aksay, I.A.; Bleier, A. Stability of aqueous-Al2O3 suspension with poly(methacrylic acid) polyelectrolyte. J. Am. Ceram. Soc. 1988, 71, 250-255. [CrossRef]

13. Parks, G.A. The isoelectric points of solid oxides, solid hydroxides, and aqueous hydroxo complex systems. Chem. Rev. 1965, 65, 177-198. [CrossRef]

14. Tokita, M. Trends in advanced SPS systems and technology. J. Soc. Powder Tech. Jpn. 1993, 30, $790-804$. [CrossRef]

15. Omori, M. Sintering, consolidation, reaction and crystal growth by the spark plasma system (SPS). Mater. Sci. Eng. A 2000, 287, 183-188. [CrossRef]

16. Munir, Z.A.; Amselmi-Tamburini, U.; Ohyanagi, M. The effect of electric field and pressure on the synthesis and consolidation of materials: A review of the Spark Plasma Sintering Method. J. Mater. Sci. 2006, 41, 763-777. [CrossRef]

17. Kumeda, K.; Nakamura, Y.; Takata, A.; Ishizaki, K. Surface observation of pulsed electric current sintered alumina balls. J. Ceram. Soc. Jpn. 1999, 107, 187-189. [CrossRef]

18. Hollenberg, G.W.; Terwilliger, G.R.; Gordon, R.S. Calculation of Stresses and Strains in Four-Point Bending Creep Tests. J. Am. Ceram. Soc. 1971, 54, 196-199. [CrossRef]

19. Singh, B.M.; Jena, J.; Laxmidhar, B.; Sarama, B. Dispersion of nano-silicon carbide (SiC) powder in aqueous suspensions. J. Nanop. Res. 2007, 9, 797-806. [CrossRef]

20. Duran, C.; Gozmez, H.; Yilmaz, H. Dispersion of mechanochemically activated $\mathrm{SiC}$ and $\mathrm{Al}_{2} \mathrm{O}_{3}$ powders. Mater. Sci. Eng. 2008, 475, 23-26. [CrossRef]

21. Briscoe, B.; Asad, U.; Lucham, F. Optimising the dispersion on an alumina suspension using commercial polyvalent electrolyte dispersants. J. Eur. Ceram. Soc. 1998, 18, 2141-2147. [CrossRef]

22. Singh, B.P.; Bhattacharjee, S.; Besra, L. Evaluation of dispersibility of aqueous alumina suspension in presence of Darvan C. Ceram. Int. 2004, 30, 939-946. [CrossRef]

23. Azar, M. Mise en Forme et Frittage des Poudres de Céramique Nanostructurées: Cas d'une Alumine de Transition; Insa de Lyon: Villeurbanne, France, 2009. (In French)

24. Cannon, R.; Langdon, T. Review creep of ceramics. J. Mater. Sci. 1988, 23, 1-20. [CrossRef]

25. Thompson, A.M.; Fang, J.; Chan, H.M.; Harmer, M.P. High temperature behaviour of alumina/SiC nanocomposites. J. Am. Ceram. Soc. 1995, 51, 671-678.

(C) 2018 by the authors. Licensee MDPI, Basel, Switzerland. This article is an open access article distributed under the terms and conditions of the Creative Commons Attribution (CC BY) license (http:/ / creativecommons.org/licenses/by/4.0/). 